\title{
Chronic rhinosinusitis as a risk factor for snoring and sleep-disorders breathing
}

\begin{abstract}
Background: In the current study, we aimed to evaluate the impact of nasal disorders breathing on sleep quality in patients with chronic nasal polyposis.

Patients and Methods: The study sample included 52 patients ( 34 men and 18 women) aged between 28 and 65 years who showed symptoms of chronic nasal obstruction due to of nasal polypos. All patients underwent functional endoscopic sinus surgery (FESS). In post-surgery period, after 4weeks of FESS 28 patients received topical corticosteroids for 2 months and anti-inflammatory or antiallergic treatment (Group 1). The remaining 24 patients took no additional post-surgical treatment (Group 2). All of the preoperative examinations and the measurements including VAS scoring for snoring, excessive daytime sleepiness using the Epworth sleepiness scale (ESS), nasal airflow, and apnea-hypopnea index (AHI) examination during sleep were repeated 3 months after the surgery.
\end{abstract}

Results: The examination results of active anterior rhinomanometry revealed that due to of therapeutic treatment in postoperation period in the patients of first group nasal airway patency increased to $742.8 \mathrm{~cm} 3 / \mathrm{s}$ while in the second group it increased to $564 \mathrm{~cm} 3 / \mathrm{s}$. In the first group the mean VAS for snoring in patients was $6.8 \pm 2.66$ preoperatively and $1.9 \pm 1.63(\mathrm{P}<0.05)$ in the last visit $(3$ months postoperatively). The mean VAS for snoring in patients in the second group was $6.2 \pm 2.64$ preoperatively, and $2.8 \pm 2.26(\mathrm{P}<0.05)$ in 3 months postoperatively. In the first group mean value of excessive daytime sleepiness decreased significantly $(\mathrm{P}<0.05)$ in the postoperative period (preoperatively, $9.2 \pm 4.1$ and postoperatively, $4.1 \pm 2.1)$ and from $8.6 \pm 3.2$ to $5.9 \pm 3.5$ in the second group $(\mathrm{P}<0.05)$. Mean $\mathrm{AHI}$ score in the first group improved significantly in the postoperative period $(7.25 \pm 3.25)$ as compared with the preoperative mean value $(19.6 \pm 4.05, \mathrm{P}<0.05)$. In the second group mean value of $\mathrm{AHI}$ was changed from $18.85 \pm 3.99$ to $11.75 \pm 5.81(\mathrm{P}<0.05)$.

Conclusion: Chronic polyposis rhinosinusitis is a risk factor for the induction or augmentation of snoring and OSAS. FESS alone has the modest efficacy on snoring, daytime sleepiness and AHI scores in comparision with the FESS combination with the medical treatment (topical corticosteroids, antiallergic and antibiotics or antifungal) in post operation period.

Keywords: snoring, sleep apnea, nasal polyps, chronic rhinosinusitis, risk factor, breathing, postoperative, nasal, surgery, patients
Volume 6 Issue 3 - 2017

\author{
Khandanyan GL,' Petrosyants Gl.2 Morsikyan \\ IK,' Ananyan GG,' Shukuryan AK' \\ 'ENT department of Yerevan State Medical University, Armenia \\ ${ }^{2}$ ENT department of Medical Center, Armenia \\ ${ }^{3}$ ENT department of Yerevan State Medical University, Armenia
}

Correspondence: Khandanyan GL ENT department of Yerevan State Medical University, Armenia,

Email khandanyan@yahoo.com

Received: November 05, 2016 | Published: March 14, 2017
Abbreviations: FESS, functional endoscopic sinus surgery; ESS, epworth sleepiness scale; AHI, apnea-hypopnea index; SDB, sleep-disordered breathing; OSAS, obstructive sleep apnea; VAS, visual analog scale

\section{Introduction}

Sleep-disordered breathing (SDB) is a spectrum of various respiratory abnormalities ranging from primary snoring to severe obstructive sleep apnea (OSAS). ${ }^{1}$ Primary snoring shows high prevalence among adults. It is estimated that $20-57 \%$ of adult population is affected. ${ }^{2,3}$ The snoring is not only a "cosmetic" issue but it compromises the quality of sleep of partner and is associated to an increased risk to develop OSAS. ${ }^{4,5}$ It is characterized by repetitive episodes of obstruction at one or more levels of upper airway during sleep. OSAS, which is a serious sleep disorder, affects nearly $2-4 \%$ of the population ${ }^{6}$ and is associated with long-term hypoxia, daytime and overnight symptoms and sleep fragmentation. ${ }^{6,7}$ OSAS and even snoring are known to be associated with many systemic diseases such as arterial hypertension, congestive heart failure, cerebrovascular incidents, pulmonary hypertension, depression and obesity. ${ }^{8-10}$ Moreover, daytime sleepiness due to OSAS has been recently reported to increase the risk of having traffic accidents. ${ }^{11}$ Thus, patients with OSAS should be treated effectively to reduce symptoms and consequences of OSAS (e.g., associated diseases causing morbidity).

Nasal breathing is the physiological route of respiration. Improvement of sleep-related breathing disorders after nasal surgeries has been reported in several studies. ${ }^{12-15}$ However, etiologic factors of nasal obstruction in these studies are heterogeneous, including inferior turbinate hypertrophy, external nose and nasal septum deviation, nasal vault deformities, chronic nasal disease such as polyposis rhinosinusitis. ${ }^{16}$ As a result, it is impossible to standardize the ratio of nasal obstruction and it is difficult to assess precisely the impact of nasal surgery on sleep quality. In the current study, we aimed to evaluate the impact of nasal disorders breathing on sleep quality in patients with chronic nasal polyposis.

\section{Materials and methods}

The study was performed collaboratively at the Department of Otorhinolaryngology (ENT) of "Erebouni" Medical Center, Yerevan, Armenia and "Sleep laboratory" of the "Center of Preventive Cardiology", Yerevan, Armenia, between 2010 and 2012. The study sample included 52 patients (34 men and 18 women) aged between 
28 and 65years who showed symptoms of chronic nasal obstruction for more than 6months and had at least $50 \%$ of obstruction of each nasal passage due to nasal polyposis on endoscopic examination (conventional anterior rhinoscopy and nasal endoscopy). We excluded from the study patients with maxillofacial deformity, central sleep apnea and other primary sleep disorders (insomnia, periodic limb movement, restless legs, parasomnias, and narcolepsy) as well as those with systemic diseases associated with sleep apnea according to their medical histories. Alongside with main complaints, the study patients also reported typical symptoms of sleep apnea, such as choking or gasping during sleep, snoring (reported by the bed partner), recurrent awakening from sleep, unrefreshing sleep, daytime fatigue, headaches, impaired concentration, nasal discharge, hyposmia or anosmia.

After receiving standard pre-surgery conservative treatment, all patients underwent functional endoscopic sinus surgery (FESS) for the removal of nasal polyps and for the treatment of chronic sinusitis. In post surgery period, after 4 weeks of FESS 28 patients received topical corticosteroids (mometasone furoate or fluticasone furoate) for 2 months and antiallergic (desloratadine or loratadine) treatment, as well as antibiotics (amoxsacillin/clavulonat or macrolides) or antifungal (fluconazole) depending on nasal swab examination results (Group 1). The remaining 24 patients took no additional post-surgical treatment (Group 2). Nasal airflow of patients was measured by active anterior rhinomanometry. Patients wore a tightfitting facemask, and with the mouth closed, breathed through one nostril. A sensor, placed in the contralateral nostril, recorded data on prenasal pressures via airflow and pressure transducers. The instrument (4 Phase RhinoLab Germany) was connected to a personal computer. The signals of transnasal airflow and pressure were amplified, digitized, and saved for statistical analysis.

Nasal airflow was reported as the sum of recorded airflow through the right and left nostrils in milliliters per second at a pressure difference of $150 \mathrm{~Pa}$ across the nasal passage. Three airflow measurements were performed for each patient and the mean was recorded. Clinical classification of obstruction and conductance of the nose was performed by 5 -grade scaling ${ }^{17}$ (Table 1 ). Severity of snoring was determined by visual analog scale (VAS), graded 0 to 10 preoperatively according to what the subject's bed partner reported ${ }^{18}$ (Table 2).

Table I Clinical classification of obstruction and conductance of the nose*

\begin{tabular}{lll}
\hline Grades & Conductance & Flow at I50Pa $(\mathbf{c c m} / \mathbf{s})$ \\
\hline 1 & Very high & $>500$ \\
2 & High & $300-500$ \\
3 & Moderate & $180-300$ \\
4 & Low & $60-180$ \\
5 & Very low & $<60$ \\
\hline
\end{tabular}

*Vogt et al. [17]

Table 2 Snoring VAS*

\begin{tabular}{ll}
\hline 0 & No snoring at all \\
3-Jan & Soft snoring not interrupting the bed partner,s sleep \\
6-Apr & Loud snoring, enough to be bothersome to the partner \\
9-Jul & Very intense snoring annoying to anyone nearby \\
10 & Bed partner leaves room \\
\hline
\end{tabular}

Overnight polysomnography was performed in all patients with "EMBLA N7000" (EMBLA System, Inc.) polysomnograph, using the program "Somnologica v. 4,0" (EMBLA System, Inc.). The monitoring included electroencephalogram $(\mathrm{C} 3 / \mathrm{A} 2, \mathrm{C} 4 / \mathrm{A} 1$ of the international electrode placement system), electrooculogram, chin and leg electromyogram, and electrocardiogram (modified V-2 lead). Respiration was investigated by oronasal airflow (thermal sensors), thoracic and abdominal movements (piezo sensors), snoring sound (microphone), and oxygen saturation (pulse oximetry). Records were scored following the Rechtschaffen and Kales international criteria for sleep/wake determination. ${ }^{19}$ As the most important parameters for determination of an OSAS, we choose the apnea-hypopnea index (AHI) during sleep. Differential diagnoses for OSAS, such as simple snoring, central sleep apnea syndrome, narcolepsy, restless leg syndrome, and so on, were excluded by polysomnography. Excessive daytime sleepiness was measured using the Epworth sleepiness scale (ESS). ${ }^{20}$ SPSS version 15.0 for Windows (SPSS, Inc, Chicago, IL) was used for statistical analysis. Statistical significance of the findings was evaluated using the paired Student's t-test for parametric data and Wilcoxon signed-rank test for nonparametric data. A threshold significance level $\mathrm{P}=0.05$ was considered statistically significant.

\section{Results}

All of the preoperative examinations and the measurements including VAS scoring for snoring, ESS scoring, nasal endoscopy, active anterior rhinomanometry, and polysomnography were repeated 3 months after the surgery. In both groups there were no significant differences between pre- and postoperative body mass indexes (BMI) (28.3 \pm 2.6 vs. $28.7 \pm 3.6, \mathrm{P}>0.05$ in first group and $29.4 \pm 3.2$ vs. $29.6 \pm 4.8, \mathrm{P}>0.05$ in second group). Ratios of nasal obstruction due to nasal polyposis were $50-75 \%$ in all patients on diagnostic endoscopy. Rhinomanometric data disclosed a significant difference between pre- and postoperative phases for both groups after 3 months in postoperation period. In first group nasal airflow $(\mathrm{cm} 3 / \mathrm{s})$ was $187.9 \pm 42.8$ in preoperation period, while after 3 months in postoperation period it was increased more than 3 times reaching $742.8 \pm 128.4(\mathrm{P}<0.05)$. In second group, the airflow was $245 \pm 86.4$ in preoperation period, and it was increased by about 1.5 times equalling $564 \pm 116.9$ in postoperation period $(\mathrm{P}<0.05)$ (Figure1). All 52 patients snorered preoperatively. Success on snoring was defined by a final snoring score on VAS of 3 or less as this score was linked with the bed partner satisfaction regarding the snoring noise.

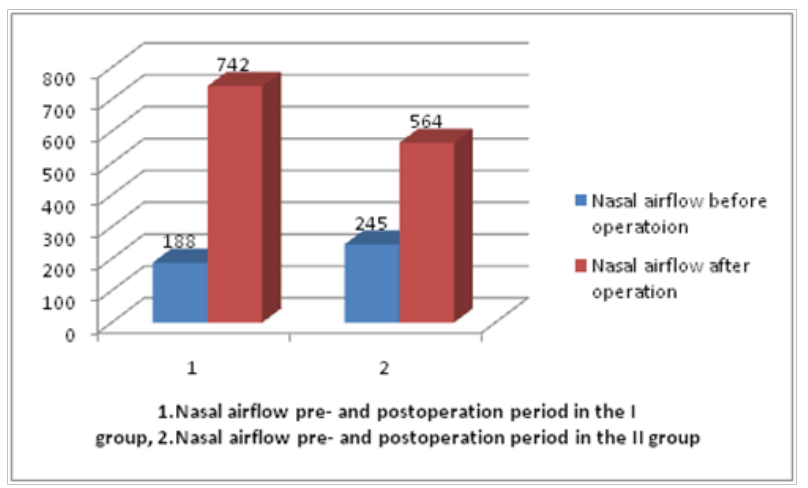

Figure I Evaluation of nasal airflow before and in post operation period.

In the first group, $18 \%$ of 28 patients had mild, $50 \%$ - moderate, $28 \%$ - severe, and the remaining $4 \%$ - very severe snoring. The mean VAS for snoring in patients of that group was $6.8 \pm 2.66$ preoperatively and $1.9 \pm 1.63(\mathrm{P}<0.05)$ in the last visit $(3$ months postoperatively). Snoring was disappeared in 13 patients $(47 \%)$, and satisfactory improvement was reported by 11 patients $(39 \%)$ in the postoperative period. $4(14 \%)$ patients' bed partners noted some decrease of sound 
snoring, but unsatisfactory of results (Figure 2). In the second group, $25 \%$ of 24 patients had mild , $58 \%$ - moderate, and $17 \%$ - severe snoring. The mean VAS for snoring in patients in the second group was $6.2 \pm 2.64$ preoperatively, and $2.8 \pm 2.26(\mathrm{P}<0.05)$ in 3 months postoperatively. Snoring was completely disappeared in 9 patients (37\%), and satisfactory improvement was reported by 10 patients $(42 \%)$ in the postoperative period. Decreases of sound snoring were noted by $4(14 \%)$ patients' bed partner, but all they were not satisfied of results (Figure 3). In the first group mean value of excessive daytime sleepiness, measured by ESS, decreased significantly $(\mathrm{P}<0.05)$ in the postoperative period (preoperatively, $9.2 \pm 4.1$ and postoperatively, $4.1 \pm 2.1(\mathrm{P}<0.05))$ and from $8.6 \pm 3.2$ to $5.9 \pm 3.5$ in the second group ( $\mathrm{P}$ $<0.05$ ) (Figure 3). Mean apnea-hypopnea index (AHI) score in the first group improved significantly in the postoperative period $(7.25 \pm 3.25)$ as compared with the preoperative mean value $(19.6 \pm 4.05, \mathrm{P}<0.05)$. In the second group mean value of AHI was changed from $18.85 \pm 3.99$ to $11.75 \pm 5.81(\mathrm{P}<0.05)$.

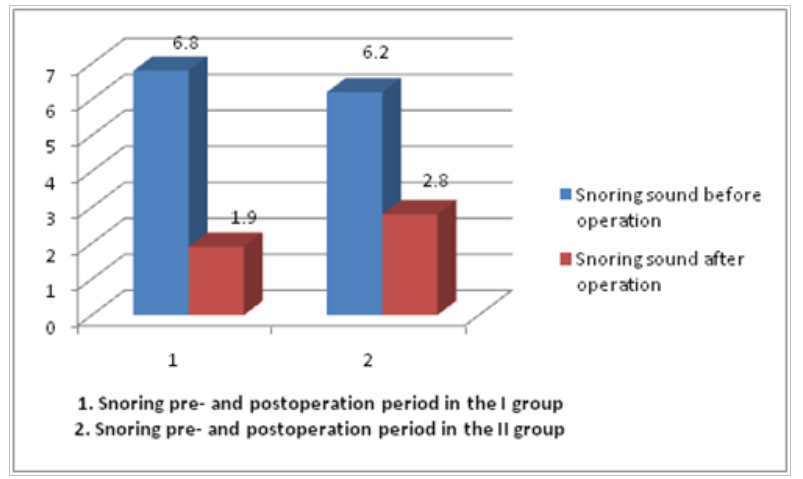

Figure 2 Evaluation of snoring based on a VAS on a I0-grade scale in pre-and postoperation period.

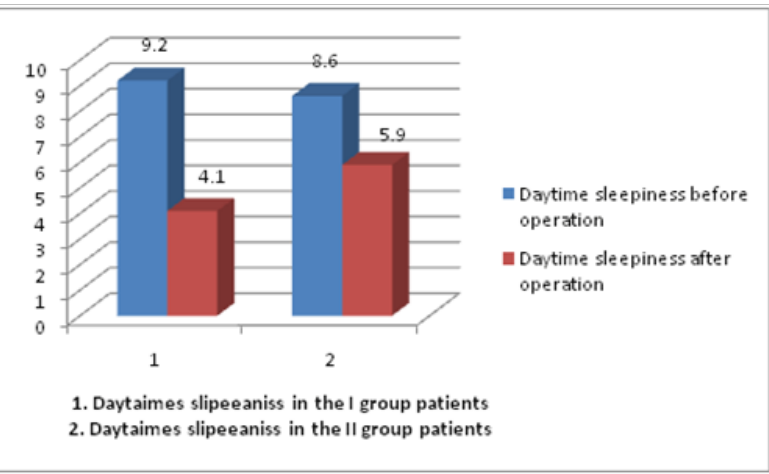

Figure 3 Evaluation of daytime sleepiness based on ESS.

\section{Discussion}

Nasal obstruction is widely mentioned among the risk factors of SDB. A number of studies have evaluated nasal surgery alone for snoring. Low found that 15 of 30 patients had snoring relief after surgery, ${ }^{21}$ whereas Ellis et al found that of 126 patients, 39 (31\%) had snoring resolution and $72(57 \%)$ had improvement in snoring. ${ }^{22}$ A study by Fairbanks found that $77 \%$ of patients had elimination or improvement of snoring after nasal surgery. ${ }^{23}$ Serrano et al. reported that $50 \%$ of patients with nasal polyposis had snoring, and these patients also had a 2-fold higher risk ratio of sleep disturbance as compared with controls. ${ }^{24}$

Because the nasal route is preferred for respiration during awake and sleep in healthy adults, it is plausible to suggest that correction of nasal obstruction may relieve sleep-related breathing disorders. Likewise, several authors report that nasal surgery produces improvement of symptoms in patients with snoring and obstructive sleep apnea. ${ }^{12,14,25}$ However, in these studies, nasal pathologies causing obstruction are different, such as the deviation of the nasal septum, the nasal vault deformities, or the inferior turbinate hypertrophies, so it is difficult to make precise comparison between the increment of nasal patency after nasal surgery and the improvement of sleep related breathing disorders. On the contrary, several studies reported no improvement of sleep-related breathing disorders after nasal surgeries and suggested further research in this field. ${ }^{26-28}$ In the current study we considered patients with chronic nasal obstruction who had at least $50 \%$ of obstruction of each nasal passage due to nasal polyposis and found that post-surgery therapy (topical corticosteroids, antiallergic or antibiotics medicines) significantly improves overall treatment outcomes. Particularly, patients reported better nasal breathing and anterior rhinomanometry revealed greater nasal airway patency increase.

In addition, post-operative therapeutic treatment resulted in better relief of snoring. A significant improvement was also obtained in ESS scores $(\mathrm{P}<0.05)$. About the similar relief in snoring and daytime sleepiness was also reported by several authors after septoplasty or turbinate surgery. ${ }^{15,24}$ In the first group FESS improved the nasal airway and conservation treatment in post operation period was facilitate to decreas AHI score from $19.6 \pm 4.05$ to $7.25 \pm 3.25(\mathrm{P}<0.05)$, yet in the second group the patients underwent only surgical treatment and improvement of nasal airway facilitated to decries AHI from from $18.85 \pm 3.99$ to $11.75 \pm 5.81(\mathrm{P}<0.05)$. Correction of chronic nasal obstruction decreases negative pressure in the nasopharynx during sleep and relieves snoring by preventing vibration of the uvula and the soft palate. The nasal passage is the natural route of respiration, and patency of nasal airway allows a comfortable sleep. Nasal obstruction is one of the etiologic factors mentioned previously. As a result, nasal surgery can be considered as one of the components of OSAS complex treatment, and nasal surgery should be combined with topical corticosterois, antiallergic and antibiotic treatment.

\section{Conclusion}

Chronic polyposis rhinosinusitis is a risk factor for the induction or augmentation of snoring and OSAS and FESS significantly improve sleep quality by relieving snoring and daytime sleepiness in patients with nasal obstruction. However, nasal surgery alone has the modest efficacy on snoring, ESS and AHI scores in comparision with the FESS combination with the medical treatment (topical corticosteroids, antiallergic or antibiotics) in post operation period.

\section{Acknowledgments}

None.

\section{Conflicts of interest}

Author declares there are no conflicts of interest.

\section{Funding}

None.

\section{References}

1. American Sleep Disorders Association International Classification of Sleep Disorders (ICSD): Diagnostic and Coding Manual. American Sleep Disorders Association, Rochester, Minnesota, USA. 1997. 21-24. 
2. Jennum P, Sjol A. Snoring, sleep apnoea and cardiovascular risk factors: the MONICA II Study. Int J Epidemiol. 1993;22(3):439-444.

3. Stradling JR. Obstructive sleep apnoea: definitions, epidemiology \& natural history. Thorax. 1995;50(6):683-689.

4. Stephen GA, Eichling PS, Quan SF. Treatment of sleep disordered, breathing and obstructive sleep apnea. Minerva Med. 2004;95(4):323-336.

5. Ohayon MM, Guilleminault C, Priest RG, et al. Snoring and breathing pauses during sleep: telephone interview survey of a United Kingdom population sample. BMJ. 1997;314(7084):860-863.

6. Young T, Evans L, Finn L, et al. Estimation of the clinically diagnosed proportion of sleep apnea syndrome in middle-aged men and women. Sleep. 1997;20(9):705-706.

7. American Academy of Sleep Medicine International classification of sleep disorders: diagnostic and coding manual, (2nd Edn), American Academy of Sleep Medicine, West-chester, USA. 2005.

8. Jennum $\mathrm{P}$, Hein $\mathrm{HO}$, Suadicani $\mathrm{P}$, et al. Cardiovascular risk factors in snorers. A cross-sectional study of 3,323 men aged 54 to 74 years: the Copenhagen male study. Chest. 1992;102(5):1371-1376.

9. Yaggi HK, Concato J, Kernan WN, et al. Obstructive sleep apnoea as a risk factor for stroke and death. N Engl J Med. 2005;353(19): 2034-2041.

10. Wolf J, Lewicka J, Narkiewicz K. Obstructive sleep apnea: an update on mechanisms and cardiovascular consequences. Nutr Metab Cardiovasc . 2007;17(3):233-240.

11. De Mello MT, Narciso FV, Tufik S, et al. Sleep disorders as a cause of motor vehicle collisions. Int J Prev Med. 2013;4(3):246-257.

12. Kim ST, Choi JH, Jeon HG, et al. Polysomnographic effects of nasal surgery for snoring and obstructive sleep apnea. Acta Otolaryngol. 2004;124(3):297-300.

13. Verse T, Maurer JT, Pirsig W. Effect of nasal surgery on sleep-related breathing disorders. Laryngoscope. 2002;112(1):64-68.

14. Elsherif I, Hussein SN. The effect of nasal surgery on snoring. Am $J$ Rhinol. 1998;12(2):77-79.

15. Friedman M, Tanyeri H, Lim JW, et al. Effect of improved nasal breathing on obstructive sleep apnea. Otolaryngol Head Neck Surg. 2000;122(1):71-74.

16. Tosun F, Kemikli K, Yetkin S, et al. Impact of endoscopic sinus surgery on sleep quality in patients with chronic nasal obstruction due to nasal polyposis. J Craniofac Surg. 2009;20(2):446-449.
17. Vogt K, Jalowayski AA, Althaus W, et al. 4-Phase-Rhinomanometry (4PR)--basics and practice 2010. Rhinol Suppl. 2010;(21):1-50.

18. Bassiouny A, El Salamawy A, Abd El-Tawab M, et al. Bipolar radiofrequency treatment for snoring with mild to moderate sleep apnea: a comparative study between the radiofrequency assisted uvulopalatoplasty technique and the channeling technique. Eur Arch Otorhinolaryngol . 2007;264(6):659-667.

19. Sleep-related breathing disorders in adults: recommendations for syndrome definition and measurement techniques in clinical research. The Report of an American Academy of Sleep Medicine Task Force. Sleep. 1999;22(5):667-689.

20. Rechtschaffen A, Kales A (Eds). A manual of standardized technology, techniques and scoring system for sleep stages of human subjects. Los Angeles, CA, Brain Information Service/Brain Research Institute, UCLA, USA, Sleep. 1968;(204):12.

21. Johns MW. A new method for measuring daytime sleepiness: the Epworth sleepiness scale. Sleep. 1991; 14(6):540-545.

22. Low WK. Can snoring relief after nasal septal surgery be predicted? Clin Otolaryngol Allied Sci. 1994;19(2):142-144.

23. Ellis PD, Harries ML, Ffowcs Williams JE, et al. The relief of snoring by nasal surgery. Clin Otolaryngol Allied Sci. 1992;17(6):525-527.

24. Fairbanks DN. Effect of nasal surgery on snoring. South Med J. 1985;78(3):268-270.

25. Serrano E, Neukirch F, Pribil C, et al. Nasal polyposis in France: impact on sleep and quality of life. J Laryngol Otol. 2005;119(7):543-549.

26. Balcerzak J, Niemczyk K, Arcimowicz M, et al. The role of functional nasal surgery in the treatment of obstructive sleep apnea syndrome. Otolaryngol Pol. 2007;61:80-84.

27. Kalam I. Objective assessment of nasal obstruction in snoring and obstructive sleep apnea patients: experience of a police authority hospital. Ann Saudi Med. 2002; 22(3-4): 158-162.

28. Virkkula P, Bachour A, HytoËnen M, et al. Snoring is not relieved by nasal surgery despite improvement in nasal resistance. Chest. 2006;129(1):81-87.

29. McNicholas W. The nose and OSA: variable nasal obstruction may be more important in pathophysiology than fixed obstruction. Eur Respir J. 2008;32(1):3-8. 